\title{
INFORMATION TECHNOLOGIES IN THE COMMAND AND CONTROL SYSTEM OF THE GENDARMERIE
}

\section{ZHIVKO ZHIVKOV}

\begin{abstract}
Bulgaria's National Service "Gendarmerie" is in the process of developing a dedicated $\mathrm{C} 2$ and management system, based on advanced communications and information technologies. The article describes this development effort and the ways it will support the functioning of the Service in securing sites of strategic importance, combating terrorist and subversive groups, protection of the public order and combating crime. A special focus is placed on the interoperability with other services in the Ministry of Home Affairs.
\end{abstract}

Keywords: Security Sector Operations, Command and Control, Operational Planning, Force Planning, Force Management, Information Systems Support, GIS, Interoperability.

Advanced management models presume adequate organizational structure. In the Management Science this structure is described as a formal system of rules, activities, authority and subordination, method of resource distribution and management, and interactions, directed towards the realization of the organizational mission. The term "structure" derives from Latin and denotes: plan, organization, internal form of a system's organization. The structure is a safeguard of the system's existence and reflects the unity of the steady regularities and reciprocal connections among its ingredients. It appears as one of the elements of the system's organization and is a combination of connections and interrelations among levels of management and various functional fields.

Structures can be examined in three main dimensions:

- Vertical differentiation of the structures, i.e. on hierarchical levels

In this dimension, the information flows and results in straight and in reverse contacts. In the straight contact, the information flows from superior to subordinate hierarchical groups, i.e. through the hierarchical route. The underlying principle is that 
on this route information does not circumvent any of the intermediate structures, because the correct functioning of the system to a significant extent depends on the availability of information on each hierarchical level. As a rule, this flow provides for the realization of specific management decisions. In the reverse contact, information is generated on subordinate levels and flows upwards, i.e. from the bottom to the top. This is an inherent part of the management process (or of 'command') as it serves as a necessary precondition for the second basic command function - the oversight. The latter provides for analysis of the results achieved, expedient correction of possible errors and accumulation of management experience. Typically, this hierarchical control can be preliminary, current and consecutive (and all of the above). In addition to these temporal forms, it has a broad coverage from the point of view of instruments used.

These characteristics are essential; therefore, hierarchical control is not only necessary and useful, but also imperative in each system.

- Horizontal differentiation of the structures along functional competencies

Here information flows horizontally. Even though necessary, the interaction among equivalent elements of the system is not obligatory in all cases, since different units can perform specific tasks independently. Therefore, the exchange of information is necessary solely when, in order to achieve a concrete result, reciprocal operations of several units are needed. In this case, there is no straight and reverse contact as in hierarchical exchanges, because the links do not have 'subordinate/ oversight' relations. In this case the term information exchange is used.

- Spatial differentiation of the structures as geographical distribution of resources, conditions and priorities of the organization

This dimension is necessary, so as the system could work on a definite territory, recognizing its specific character. The system cannot function outside its surrounding material reality, i.e., it always works in a specific environment with certain (and often changing) characteristics. Therefore, and with a view of expedience and appropriateness of the system's operations, the examination of this third dimension of activity is also necessary.

\section{The Ministry of Home Affairs ${ }^{1}$ /MHA/ - Leadership and Management Characteristics}

The Government exercises its role towards MHA in two ways - indirect and direct. As 'indirect' we consider the way of governance through laws and other decisions of the legislature, ${ }^{2}$ decrees and other regulatory documents issued by the Council of Ministers. 
Direct leading functions towards MHA as a whole and towards the National Gendarmerie Service /NGS/ in particular are carried out by the President and the Minister of the Interior in conformity with the respective jurisdiction. The Minister of the Interior implements the decisions of the National Assembly and the Council of Ministers, realizes in practice the Government's policy in the areas of national security, defense ${ }^{3}$ and public order. In the exercise of these powers, he or she is assisted by a Political Cabinet with consultative and information-analytical functions and three deputy ministers. The deputies perform functions assigned to them by the Minister. The senior ranking professional in the MHA is the Chief Secretary. He organizes and controls the main activities of the Ministry and oversees the interaction among all MHS Services and other departments.

The organization and the management of the MHA Services and Departments are carried out in accordance with the principle of centralism.

Services' structures are constructed along the following principles:

- Optimum number of personnel on each hierarchical level;

- Ensuring the shortest possible way for information exchange;

- Stability, with opportunity for certain alterations to reflect changes of the operational environment;

- Effective distribution of the resources.

National and regional services and directorates of the MHA are managed by Directors, who perform direct management of the units, organize, administer and bear responsibility for their activity, provide methodological guidance to the regional structures, coordinate the interaction with other state institutions, manage the information resources, conduct the international collaboration with corresponding foreign agencies, manage the human resources and state property, placed at their disposal, undertake punitive measures and enforce administrative compulsion.

\section{The National Gendarmerie Service /NGS/ - Structural and Management Characteristics}

National Gendarmerie Service /NGS/ is a specialized security, operational and investigation police service of the MHA that provides for security of strategic and particularly important sites, combating terrorist and subversive groups, protection of the public order and combating crime.

NGS duties are performed through the following structures: Directorate, Brigade, units, and a specialized aviation unit. 
The Directorate administers the entire service, plans all its activities, organizes and manages the accomplishment of the tasks for securing strategic and essentially important sites, combating terrorist and subversive groups and protection of public order out of cities, towns, and villages, organizes the fulfillment of NGS tasks in emergency and crisis situations, manages the human resources, administers the combat and the mobilization readiness, conducts the international collaboration with the corresponding foreign agencies.

The Directorate performs the operative management through Structural Units which collect, analyze and evaluate the operational situation data in the country, offers plans and suggestions for solutions to the Director of the NGS, coordinates the interaction with regional institutions of the Government and with the Regional Directorates of the MHS, develops and maintains plans for such interaction.

The tactical command of the NGS Structural Units is exercised by Commanders, who are in charge of:

- Planning, organizing and managing the activity of the respective units;

- Organizing the fulfillment of orders by the Superior Commander.

The commanders of Structural Units are responsible to the Director for the entire activity of their units, and to his deputies in accordance with the specific distribution of functional responsibilities.

Currently, the structure of NGS and its units corresponds to the contemporary requirements, assigned tasks and activities, and provides for high quality execution of responsibilities. In addition, our understanding is that this structure would not remain static, but it should reflect and even be ahead of the dynamic changes of the social relations.

\section{The Information Activity in the NGS C2 (Management and Control) Systems}

The Information Activity (IA) in the NGS is built in conformity with the MHA Law, National Strategy for the IA in the MHA, the Concept and the Program for restructuring of the NGS and is directed at collecting, systematizing, preserving, analyzing, utilizing and delivering information. It provides for the operational and the management activities of the NGS administration, the coordination and the interaction with the MHA and other national services and administrations.

The underlying priorities of the IA are directed at ensuring the fulfillment of the tasks assigned by law, in particular the tasks to secure critical sites, to protect public order, to counteract crime and fight terrorism. 
The information infrastructure includes:

- Structural plan and sufficient personnel for the IA of the NGS;

- Structural cable systems and connection of all Structural Units with the communications system of the MHA;

- Technical equipment;

- Advanced protection system.

The integration of the NGS communications system is being implemented through:

- A network for transmission of data. NGS utilizes the MHA network for transmission of data and information. The NGS Regional Units and its Directorate are connected to the MHA network via high frequency (fiber optic) channels.

- E-mail. "Computer posts" for information transmission through the MHA mail services are being established in the NGS Directorate and its Regional Units.

- $\quad$ Phone and radio communications. Phone and radio communications are used to connect mobile units with the NGS Directorate. The communications system is managed by a Central Control Post (Operational Duty Center), established in the Directorate of the NGS. NGS uses the MHA phone network and an independent radio-communications system that includes advanced communications features, such as data transmission.

IT procurement at NGS aims at:

- Providing hardware and software components for Automatic Work Places /AWP/, established in accordance with the existing structural scheme of the IA in NGS;

- Ensuring the effectiveness of each AWP by installing and maintaining of the necessary information systems;

- Providing access to the relevant Automated Information Systems of the MHA and of other governmental agencies;

- Applying the integrated system for criminal analysis in accordance with the EU standards;

- Stabilizing the capacity for criminal analysis with the purpose to increase the effectiveness of combating crime;

- Increasing the qualification of the personnel;

- Developing organizational-management materials and normative acts, aimed at improving the organization and the effectiveness of using the information technologies. 
The information activity in NGS aims at:

- Provision of information necessary to support the NGS operational and management activity;

- Information-analytical support;

- Supporting the interaction of NGS with other structures of the MHA, state authorities and organizations;

- Integration into the IA of the MHA.

NGS maintains the following information flows:

- Information exchange and support for the interaction with the other MHA Services and Directorates;

- Exchange of operational information between the Operatives on Duty of the MHA and the Structural Units in the NGS;

- Utilization of the information from the Central Automated Information System;

- Development and exchange of information-analytical materials on the operational situation with the MHA, National Services, Regional Structural Units and other state institutions;

- Exchange of information on the maintenance and the provisional activity.

The Directorate of the National Gendarmerie organizes and administers the entire management of the IA of the Service. It assigns the new information requirements and requests, initiates the realization of the means for information procurement and takes part in the entire development of the IA. In addition, the Directorate provides for the use of components from the Information Funds for common use. Finally, it organizes and protects the information, the technologies and the resources.

The NGS specialized information sections work towards comprehensive information support to the management and the information-analytical activity of the Service in accordance with the assigned functions, such as:

- Activity planning;

- Organizing fulfillment of tasks;

- Analyzing, evaluating and delivering information;

- Coordinating plans and interactions;

- Assisting organizational leaders in managing the structures.

The NGS organizes and performs information exchange with integrated state systems for collecting and arranging information for the basic information objects in the State Information Systems. 
The information-analytical activity is realized when estimating the condition, reliability and representativeness of the current information and supplementing it with designated information, results of sociological studies, etc. In this process, quantitative data is statistically arranged and presented respectively. Results and conclusions of the information-analytical activity are stored as part of the basic knowledge in the MHA (this is in contrast to storing raw data with various levels of reliability).

\section{Acquisition of Information and Procurement of IT in the NGS C2 System}

The information activity is in conformity with the specificity and the dynamics of the assignments executed by the NGS, IT advances, and the MHA Concept and Strategy on information activity.

The development of the information infrastructure of NGS is intended to:

- Expand the net-range for transmission of data to the MHA through computerization of the Regional Structures and building structural cable systems in the NGS stationary structures;

- Increase the speed and the quality of the information exchange among the NGS Directorate and the Regional Structures of the Service;

- Develop the information protection policy;

- Improve the connections with the mobile structures of the NGS;

- Utilize GPS devices to follow the movement of the NGS mobile patrols.

The development of information provisions of NGS is intended to:

- Utilize more effectively existing (in the MHA) Automatic Information Systems and advanced IT tools;

- Improve training in the area of information technologies;

- Implement specialized information technologies to ensure robust performance in extreme and crisis situations, during massive violations of public order, etc.;

- Develop and implement automated Information Funds in the NGS to support the management activity of the NGS Directorate. Such funds are intended to support the management activity of the NGS Directorate, as well as other structures of the MHA according to their competence, in a regulated manner. The data bases and the specialized applications will run on a central server in the NGS Directorate; the AWPs of the system on brigade and unit level will run client software. Clients will connect to the server through the MHA network. The AWPs are equipped with workstations (PCs) and software ac- 
cording to the system architecture and the communications system environment of the MHA.

- Implement Automated Geographic System for situation management of the NGS forces. This system should utilize advanced communications and information technologies in order to provide real-time situational awareness (to include fusion of information from the database with information on the geographic location of NGS forces, their condition and current activities). In addition, the system should incorporate plans for reaction of the NGS in particular situations; the implementation of certain plans will be initiated upon receiving information in the NGS Fund on changes in the operational situation.

The connections with mobile units are realized using devices for transmitting and transforming voice and data.

The standard and application software should be compatible with the other Information Systems used in the MHA.

Currently, and not by chance, we describe society as 'civic,' but also as 'information society.' These two features of contemporary society are connected and interrelated; information is seen as essential product of the functioning of society. The concept that the armed forces, including military and police forces, are instruments for support of the power of the state is long foregone. Currently, these 'power' institutions are seen as instruments for promoting the interests of society institutions; they offer services, their 'product' is societal security, safety and tranquility. Therefore, in order to provide their 'product' effectively and without interruption, their structure and activity should reflect the requirements of the information society.

The NGS has already initiated its information activity. The role of this activity will grow in the future. This is an essential element and inseparable component of any operational, management and technological activity, as well as main responsibility of the respective specialized structures in the NGS. 


\section{Notes:}

1 Often translated also as 'Ministry of the Interior' (MoI). The MoI is the main law enforcement agency in the executive branch. The National Service "Gendarmerie" is one of the services within this Ministry.

2 Bulgaria's one-chamber parliament is known as the 'National Assembly.'

3 To the extent the MHS performs certain defense tasks.

Major General ZHIVKO ZHIVKOV is Director of the National Service "Gendarmerie" since July 2000. In 1983, he graduated the "V. Levski" Military Academy in Veliko Tarnovo, and in 1995 - "G.S. Rakovski" Defence and Staff College in Sofia, Bulgaria. He has served in variety of command positions in the troops of the Ministry of Home Affairs, and was promoted to the rank of General in 2002. 